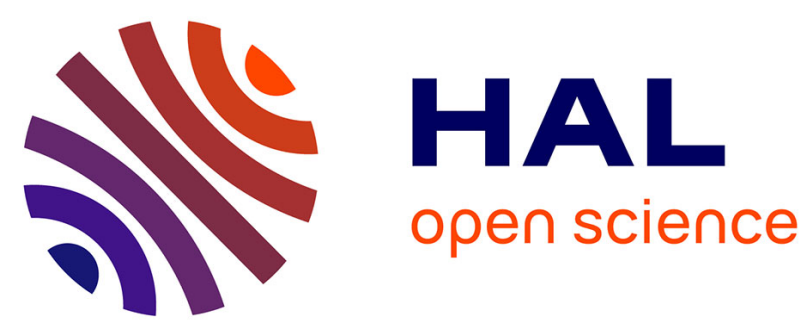

\title{
Preparation and characterization of Fe-Si-B thin films
}

\author{
M. Satalkar, S. N. Kane, Alexandre Pasko, A. Apolinario, C. T. Sousa, J.
}

Ventura, J. J. Belo, J. M. Teixeira, J. P. Araujo, F. Mazaleyrat, et al.

\section{To cite this version:}

M. Satalkar, S. N. Kane, Alexandre Pasko, A. Apolinario, C. T. Sousa, et al.. Preparation and characterization of Fe-Si-B thin films. 57th DAE Solid State Physics Symposium 2012, Dec 2012, Bombay, Mumbai, India. pp.654-655, 10.1063/1.4791207 . hal-01734917

\section{HAL Id: hal-01734917 \\ https://hal.science/hal-01734917}

Submitted on 15 Mar 2018

HAL is a multi-disciplinary open access archive for the deposit and dissemination of scientific research documents, whether they are published or not. The documents may come from teaching and research institutions in France or abroad, or from public or private research centers.
L'archive ouverte pluridisciplinaire HAL, est destinée au dépôt et à la diffusion de documents scientifiques de niveau recherche, publiés ou non, émanant des établissements d'enseignement et de recherche français ou étrangers, des laboratoires publics ou privés. 


\title{
Preparation And Characterization Of Fe-Si-B Thin Films
}

\author{
M. Satalkar ${ }^{1 *}$, S. N. Kane ${ }^{1,+}$, A. Pasko ${ }^{2}$, A. Apolinário ${ }^{3}$, C. T. Sousa ${ }^{3}$, J. Ventura $^{3}$, \\ J. J. Belo ${ }^{3}$, J. M. Teixeira ${ }^{3}$, J. P. Araujo ${ }^{3}$, F. Mazaleyrat $^{2}$, E. Fleury ${ }^{4}$ \\ ${ }^{1}$ School of Physics, D. A. University, Khandwa Road, Indore - 452001, India \\ ${ }^{2}$ SATIE, UMR CNRS 8029, ENS de Cachan, 61, Avenue du Président Wilson, 94235 Cachan, France \\ ${ }^{3}$ IFIMUP, Departamento de Fisica, Universidade de Porto, 4169-007 Porto, Portugal \\ ${ }^{4}$ Korea Institute of Science and Technology, Seoul 136-791, South Korea \\ "satalkar.manvi@gmail.com, ${ }^{+}$kane_sn@yahoo.com
}

\begin{abstract}
Thickness dependence of structural and magnetic properties of $\mathrm{Fe}_{79} \mathrm{Si}_{8} \mathrm{~B}_{13}$ films has been studied using magnetic measurements, X-ray diffraction (XRD) and scanning electron microscopy (SEM). Prepared films exhibit the presence of nanocrystalline $\alpha-\mathrm{Fe}$ phase embedded in amorphous matrix. Magnetic measurements show their homogeneous nature (within film plane). Direction perpendicular to film plane is the hard direction of magnetization. A cross-sectional SEM measurement provides film thickness. SEM also reveals the granular structure of the films.
\end{abstract}

Keywords: Hysteresis measurements, SEM, XRD.

PACS: 61.05.cn, 68.37.Hk, 75.30.Gw, 75.70.Rf

\section{INTRODUCTION AND EXPERIMENTS}

In order to utilize the soft magnetic properties of amorphous and nanocrystalline films at their best, an understanding of their structural and magnetic properties is required. The film thickness strongly influences some important physical and chemical properties, such as composition, atomic order, stresses, magnetic anisotropy, etc. [1]. As a function of thickness, significant variations are observed in the coercive field [2]. Hence, in the present work we report the thickness dependence of magnetic and structural properties of $\mathrm{Fe}_{79} \mathrm{Si}_{8} \mathrm{~B}_{13}$ films.

Amorphous ribbons of nominal composition $\mathrm{Fe}_{79} \mathrm{Si}_{8} \mathrm{~B}_{13}$ were used to deposit thin films on $\mathrm{Si}$ substrate using thermal evaporation method. Film of thicknesses: $110 \mathrm{~nm}, 160 \mathrm{~nm}$ and $170 \mathrm{~nm}$ were prepared. Hysteresis loops of the deposited thin films having different thicknesses were measured using LakeShore Model 7410 vibrating sample magnetometer (VSM) with a maximum applied field of \pm 1000 Oe. Magneto-optical Kerr effect (MOKE) hysteresis loops of the samples with different thickness were done in using $\mathrm{He}-\mathrm{Ne}$ laser of wavelength 632.8 $\mathrm{nm}$ [3]. In film-plane magnetic field of \pm 200 Oe was applied using a pair of Helmholtz coils. X-ray diffraction measurements were done using a Siemens D5000 diffractometer, with $\mathrm{Cu}-\mathrm{K}_{\alpha}$ radiation $(\lambda=0.154$ $\mathrm{nm})$. Low-vacuum scanning electron microscopy
(SEM) imaging of the surfaces was performed with an FEI Quanta 400FEG.

\section{RESULTS AND DISCUSSIONS}

Table 1 summarizes the coercivity values $\left(\boldsymbol{H}_{\boldsymbol{c}}\right)$ of the studied thin films, obtained using VSM and MOKE measurements. Perusal of table 1 shows thickness dependence of in-plane $\boldsymbol{H}_{\boldsymbol{c}}$ values along two orthogonal directions. $\boldsymbol{H}_{\boldsymbol{c}}$ values obtained from the measurement with the field applied perpendicular to film plane shows much higher values, suggesting that this direction is the hard direction of magnetization. As a function of thickness, significant variation in coercivity is seen (Table 1). It is worth noting that combining MOKE and VSM data, provides information on magnetic properties as a function of thickness. MOKE would provide magnetic signal from the layer $(\sim 30 \mathrm{~nm})$ up to which the laser penetrates within the

TABLE 1. Coercivity obtained from MOKE and VSM data, where $\boldsymbol{t}$-Sample thickness, $\boldsymbol{H}_{\boldsymbol{c}}$ - Coercivity

\begin{tabular}{ccc}
\hline \multicolumn{3}{c}{$\boldsymbol{H}_{\boldsymbol{c}}$ (Oe) obtained from } \\
\hline $\mathbf{t}(\mathbf{n m})$ & MOKE Data & VSM Data \\
\hline 110 & $81.86^{*}, 83.38^{*}$ & $86.5^{*}, 82.01^{*}, 490.03^{+}$ \\
160 & $8.09^{*}, 13.39^{*}$ & $6.17^{*}, 12.30^{*}, 156.04^{+}$ \\
170 & $12.49^{*}, 10.44^{*}$ & $11.04^{*}, 10.77^{*}, 314.81^{+}$ \\
\hline *Two orthogonal measurements in film plane, \\
+Measurement done perpendicular to film plane \\
\hline
\end{tabular}



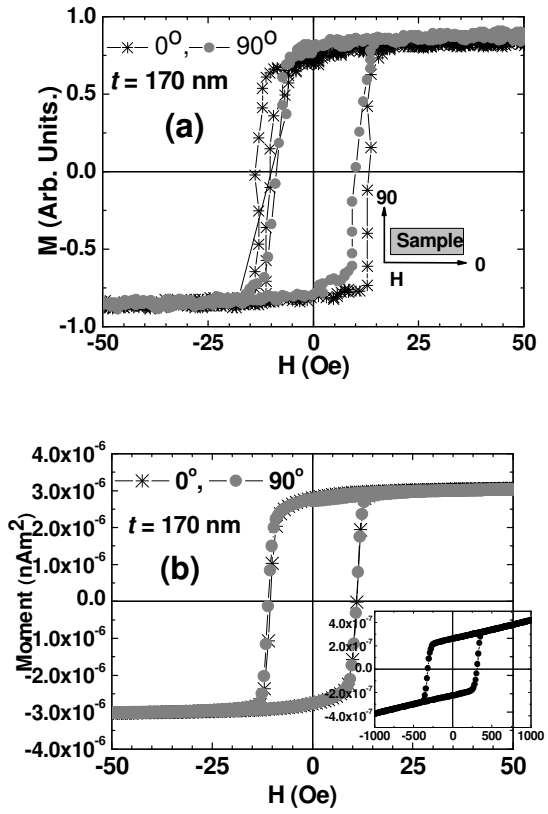

FIGURE 1. (a) and (b) respectively depicts the representative MOKE and VSM loops. Inset: Loop measured perpendicular to the film plane.

film, whereas the VSM provides signal from the whole sample. Thus, variation of magnetic properties as a function of thickness is reflected in the $\boldsymbol{H}_{\boldsymbol{c}}$, obtained from MOKE and VSM data. Table 1 also shows that within the film plane values of $\boldsymbol{H}_{\boldsymbol{c}}$ obtained from both the measurements are quite comparable, and the observed difference can be ascribed to the variation in the surface roughness, as can be seen in SEM images (Fig. 2) and the variation in the grain size (Table 2).

Figures $1 \mathrm{a}$ and $1 \mathrm{~b}$ respectively depict the representative MOKE and VSM loops of the film of thickness $170 \mathrm{~nm}$. The VSM loop measured perpendicular to the film plane is shown as inset, and the observed behavior is ascribable to randomly oriented exchange coupled particles. The out-of-plane hardness is attributed to the shape anisotropy. Perusal of figure 1 shows that the obtained $\boldsymbol{H}_{\boldsymbol{c}}$ is rather similar, revealing homogeneous magnetic properties within the film plane.

Table 2 depicts the parameters of XRD analysis. It also reveals that films consist of amorphous and nanocrystalline $\alpha$-Fe phase. $\boldsymbol{D}$ and $\boldsymbol{V}_{\boldsymbol{x}}$ of the crystalline phase range respectively between $30-34 \mathrm{~nm}$ and $35-$

TABLE 2. XRD analysis parameters; $\boldsymbol{t}$ - sample thickness, $\boldsymbol{a}$ - Lattice parameter, $\boldsymbol{D}$ - Average grain diameter, $V_{x}$ - Volume fraction of the nanograins

\begin{tabular}{cccc}
\hline $\boldsymbol{t}(\mathbf{n m})$ & $\boldsymbol{a}(\mathbf{n m})$ & $\boldsymbol{D}(\mathbf{n m})$ & $\boldsymbol{V}_{\boldsymbol{x}}(\boldsymbol{\%})$ \\
\hline 110 & $0.2876 \pm 0.0002$ & $30 \pm 3$ & $37 \pm 4$ \\
160 & 0.2856 & 34 & 41 \\
170 & 0.2855 & 32 & 35 \\
\hline
\end{tabular}

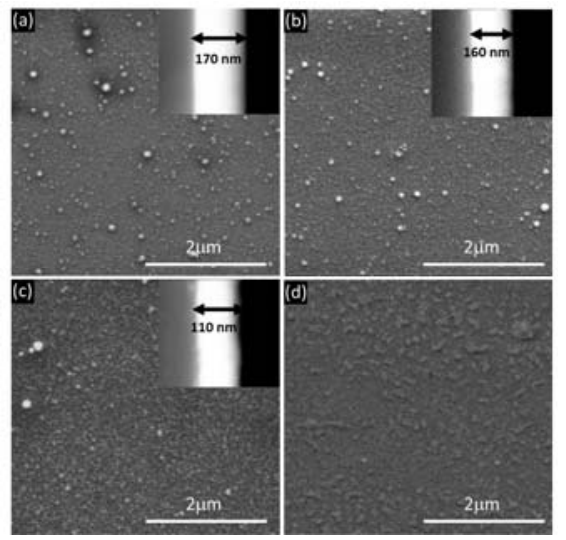

FIGURE 2. Topographic images of the thin films surface and cross section views (insets). The secondary SEM images show the surface views of the samples with several thicknesses (a) $170 \mathrm{~nm}$ (b) $160 \mathrm{~nm}$ and (c) $110 \mathrm{~nm}$; (d) shows a representative backscattered SEM image of a surface view.

$41 \%$. Variation in film thickness affects $\boldsymbol{D}$ and $\boldsymbol{V}_{\boldsymbol{x}}$. The first near-neighbour distance in amorphous phase: $0.248 \pm 0.001 \mathrm{~nm}$ remains unchanged, revealing similar mass density in the prepared specimens.

Figure 2 shows that the studied samples have granular structure, which changes with the film thickness. Insets give information on film thickness. The crystalline phase appears also to be more uniformly distributed within the amorphous matrix.

To summarize, thickness dependent magnetic and structural studies of $\mathrm{Fe}_{79} \mathrm{Si}_{8} \mathrm{~B}_{13}$ thin films are reported. Prepared films display a co-existence of amorphous and nanocrystalline $\alpha$-Fe phase, whose volume fraction varies with film thickness. Both MOKE and VSM study reveal that the prepared films are fairly isotropic within film plane. The direction perpendicular to film plane is the hard direction of magnetization.

\section{ACKNOWLEDGEMENTS}

SNK thanks for a visit at IFIMUP (Portugal), ENS de Cachan (France), May-June 2012. JMT is thankful for a FCT post-doc. grant (SFRH/BPD/72329/2010).

\section{REFERENCES}

1. P. Sharma, H. Kimura, A. Inoue, E. Arenholz, J. H. Guo, Phys. Rev. B 73052401 (2006); A. D. C. Viegas, M. A. Correa, L. Santi, R. B. da Silva, F. Bohn, M. Carara, R L. Sommer, J. Appl. Phys. 101033908 - 033914 (2007).

2. T. A. Moore, J. Rothman, Y. B. Xu, J. A. C. Bland, J. Appl. Phys. 897018 (2001).

3. J. M. Teixeira, R. Lusche, J. Ventura, R. Fermento, F. Carpinteiro, J. P. Araujo, J. B. Sousa, S. Cardoso, and P. P. Freitas, Rev. Sci. Instrum. 82043902 (2011). 